\title{
Ground motion earthquake scenario parameters for the 2009 Abruzzo earthquake
}

\author{
M. Maugeri \& S. Grasso \\ Department of Civil and Environmental Engineering, \\ University of Catania, Italy
}

\begin{abstract}
The evaluation of the seismic action, which the structures must withstand, is the most critical item of the full process of analysis, monitoring and mitigation of seismic risk. Seismic action has been recorded worldwide for moderate to severe earthquakes. In the last 30 years the recorded accelerations have been significantly increased. One reason could be the increasing number of recording stations and the location of many such stations on soft soil, where significant site amplification can occur. In many cases, the recorded accelerations have exceeded the designed acceleration given by seismic codes. This is particularly true in the case of a strong earthquake, when the evaluation of seismic action given by source mechanism results, in some cases, in a seismic design earthquake greater than that given by the probabilistic evaluation reported by the codes. Also in the case of the moderate $M_{\mathrm{L}}=5.8$ Abruzzo earthquake, the recorded acceleration exceeded the provisions given by Italian Code. Mainly two factors could explain that. One factor is related to the different results obtained by the probabilistic evaluation of seismic action given by the codes and the deterministic seismic action evaluated by source modelling of the scenario earthquake. The second factor is related to the role of site amplification, which is higher for small to moderate earthquakes and lower for severe scenario earthquakes. These two factors are discussed for the case of the Abruzzo 2009 earthquake where, because of the normal fault mechanism, severe vertical components of the acceleration were recorded; also significant site effects occurred, particularly in the Aterno valley.
\end{abstract}




\section{Introduction}

The prevention of seismic damage is a challenge for the third millennium. In spite of the significant analytical and experimental work to reduce seismic risk, the latter has been increasing exponentially in the past century.

The evaluation of the seismic action, which the structures must withstand is the most critical item of the full process of analysis, monitoring and mitigation of seismic risk. Seismic action has been recorded worldwide for moderate to severe earthquakes. In the last 30 years the number of recorded accelerations has been significantly increased. This could be partly due to the increasing number of recording stations and to the location of many such stations on soft soil, where significant site amplification can occur. Due to the increased values of recorded acceleration, the design acceleration given by the codes has been significantly increased; also some other parameters such velocity and displacement have been included in the Code for the design of buildings and infrastructures.

By the way, the recorded accelerations trend is still higher than the design acceleration given by National and International Codes, so the structures must withstand earthquakes with acceleration greater than that used for the design.

This is particularly true in the case of strong earthquakes, when the evaluation of seismic action given by source mechanism results, in some cases, in a seismic design earthquake greater than that given by the probabilistic evaluation reported by the codes, as will be explained in section 2 .

Also in the case of the moderate $M_{\mathrm{L}}=5.8$ Abruzzo earthquake, the recorded acceleration exceeded the provisions given by Italian Code, as will be shown in the section 3. Mainly two factors could explain that. One factor is related to the different results obtained by the probabilistic evaluation of seismic action given by the codes and the deterministic seismic action evaluated by source modelling of the scenario earthquake. Incidentally, the Abruzzo earthquake was characterised by a normal fault, which gave in the central area a significant vertical component, which is in general underestimated by the Codes.

The second factor is related to the role of site amplification, which is higher for small to moderate earthquakes and lower for severe scenario earthquakes. The amplification factor is discussed in the section 4. Amplification factors are comparable with the stratigraphic amplification factors given by the Italian Code [1], while in the Aterno valley the amplification factors exceed those given by the Code.

\section{Seismic action recorded during recent earthquakes}

In the last 20 years the seismic acceleration recorded during strong earthquakes has been increased considerably. Maugeri et al. [2] show that for severe earthquakes the acceleration recorded exceeds almost $0.8 \mathrm{~g}$ (table 1). This does not mean that seismicity has been increasing in the last period. The increase in the recorded acceleration could depend on the increasing number of recording stations and also on the fact that these recorded stations have been located recently in soft soil deposits, while in the past they were located on rock. Higher values of 
acceleration than those reported in table 1 have been recorded during recent earthquakes such as the 2004 Niigata Chuetsu [3], the 2007 Perù and the 2011 Sendai earthquakes, when the acceleration exceeded $2 \mathrm{~g}$.

Table 1: Acceleration recorded during destructive earthquakes in the last 20 years ([2], modified).

\begin{tabular}{|c|c|c|}
\hline Località & Nazione & A $_{\max }$ recorded (g) \\
\hline Landheers (1992) & USA & 0.86 \\
\hline Kushiro-BRI (1993) & Japan & 0.73 \\
\hline Northridge(1994) & USA & 0.91 \\
\hline Sylimar (1994) & Japan & 0.84 \\
\hline Tarzana (1994) & Japan & 1.78 \\
\hline Kobe (1995) & Japan & 0.83 \\
\hline Fukiai (1995) & Japan & 0.82 \\
\hline Kocaeli (1999) & Turkey & $>0.8$ \\
\hline Chi-Chi (1999) & Taiwan & 1.01 \\
\hline Tattoni-Ken Seibu (2001) & Japan & 0.95 \\
\hline
\end{tabular}

Because of the increase in the recorded acceleration, the National seismic codes increased the design acceleration, year by year, as reported in table 2 .

Table 2: Peak ground accelerations and design criteria [4].

\begin{tabular}{|c|c|c|c|}
\hline Year & $70 \quad 75$ & 95 & 05 \\
\hline Seismicity & $\begin{array}{l}200-300 \\
\text { gal }\end{array}$ & $00-500 \mathrm{gal}$ & $600-800 \mathrm{gal}$ \\
\hline $\begin{array}{l}\text { Nuclear } \\
\text { power } \\
\text { facilities }\end{array}$ & Equi & ivalent Liner analysis & Strengthening \\
\hline $\begin{array}{l}\text { Structures } \\
\text { (Buildings, } \\
\text { Bridges) }\end{array}$ & \begin{tabular}{l|l}
$\begin{array}{l}\text { Pseudo } \\
\text { static } \\
\text { analysis }\end{array}$ & $\begin{array}{l}\text { Linear } \\
\text { analysis }\end{array}$ \\
\end{tabular} & $\begin{array}{l}\text { Non-linear } \\
\text { analysis }\end{array}$ & $\begin{array}{l}\text { Vibration control } \\
\text { Isolation }\end{array}$ \\
\hline $\begin{array}{l}\text { Geotechnics } \\
\text { (Liquefaction, } \\
\text { Landslide, } \\
\text { Soil structure } \\
\text { interaction) }\end{array}$ & $\begin{array}{l}\text { Pseudo-static } \\
\text { analysis } \\
\qquad\left(F_{\mathrm{s}}>1.2\right)\end{array}$ & $\begin{array}{l}\text { - Equivalent linear } \\
\text { analysis } \\
\text { - Effective stress- } \\
\text { based analysis }\end{array}$ & $\begin{array}{l}\text { - Permanent displacement } \\
\text { analysis } \\
\text { - Performance-based } \\
\text { design } \\
\text { - Hazard map. Risk map } \\
\end{array}$ \\
\hline
\end{tabular}


To allow the structures to withstand these greater accelerations, the methods of analysis to be used have been refined. The pseudo-static analysis is commonly used up to $0.3 \mathrm{~g}$ for structures (buildings and bridges) and about up to $0.4 \mathrm{~g}$ for geotechnical analysis. For an acceleration level of $0.4-0.5 \mathrm{~g}$, it is more convenient to move from pseudo-static analysis to nonlinear analysis for structures and linear equivalent analysis for geotechnical works. For acceleration levels of about 0.6-0.8 g, vibration control by isolation is required for structures [5] and permanent displacement analysis and performance-based design are required for geotechnical works. Perhaps in the near future, the design acceleration will still be increased, particularly for nuclear power facilities and for strategic buildings (such as hospitals and fire stations). It must also be considered that the expected acceleration given by National Codes is given by a probabilistic approach. For instance in Italy, according to the Italian Regulation [1], the design acceleration is that which has a probability of exceedance less than $10 \%$ in 50 years; this corresponds to a return period of 475 years. In different countries, a big earthquake with a longer return period of up to 2375 years is also considered. An alternative way to evaluate the seismic action, which the buildings must withstand is given by the deterministic analysis based on the maximum credible earthquake. In this case a source mechanism will be modelled; the shear wave propagation attenuation is taken into consideration, as well as the amplification given at the surface by site effects. These two ways of evaluation of seismic action could lead to different results. For instance in the case of the seismic risk evaluation of the city of Catania (Italy), the probabilistic evaluation according to Italian Code gives an expected acceleration (fig. 1) considerably lower than the acceleration given by the deterministic approach (fig. 2).

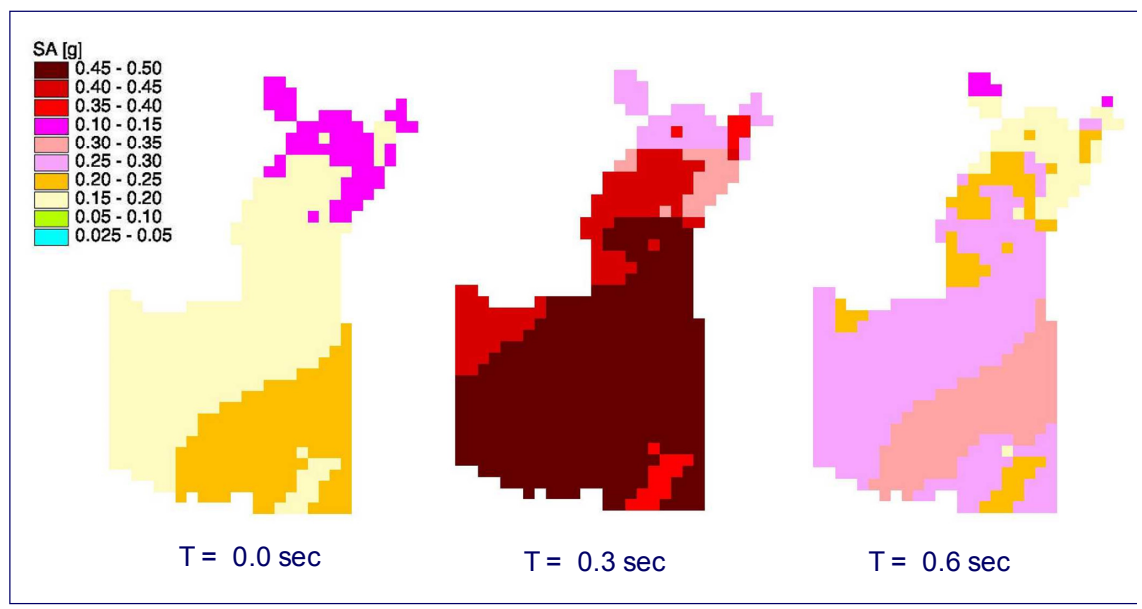

Figure 1: Probabilistic evaluation of spectral acceleration at the city of Catania (Italy) for different periods $T$ [6]. 


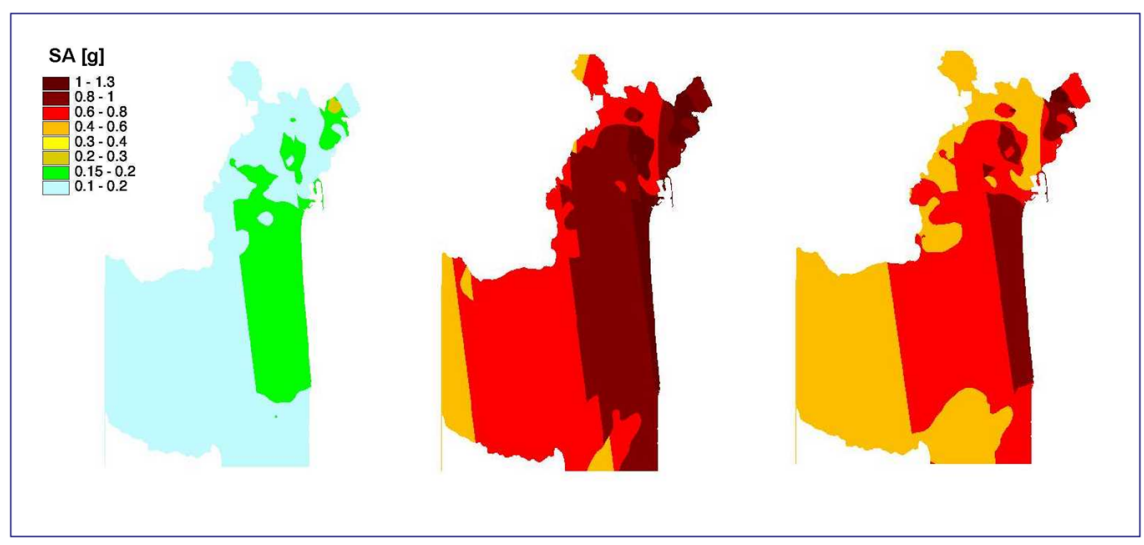

Figure 2: Deterministic evaluation of spectral acceleration at the city of Catania (Italy) for different periods $T[6]$.

In general, in Italy, when one is dealing with a maximum credible earthquake with a magnitude $M=7.0$ or greater, as in the case of the city of Catania, the deterministic approach gives a spectral acceleration value bigger than that from the probabilistic approach. In contrast, when one is dealing with a maximum credible earthquake with a magnitude $M=5.5$ or lower, it is the probabilistic approach which gives a spectral acceleration value greater than that from the deterministic approach.

In table 3, a comparison is reported between the expected probabilistic evaluation of peak acceleration, with a probability of exceedance less than $10 \%$ in 50 years, and the observed acceleration during destructive earthquakes [7]. It is possible to see that the observed acceleration always exceeds the expected probabilistic values, particularly for the case of the $2003 \mathrm{Bam}\left(M_{\mathrm{W}}=6.6\right)$, the 2010 Haiti $\left(M_{\mathrm{W}}=7.0\right)$ and the 2011 Sendai $\left(M_{\mathrm{W}}=9.0\right)$ earthquakes.

Table 3: Comparison between expected probabilistic evaluation of peak acceleration $(\% \mathrm{~g})$, with a probability of exceedance less than $10 \%$ in 50 years, and the observed acceleration during destructive earthquakes [7].

\begin{tabular}{|c|c|c|}
\hline & EXPECTED & OBSERVED \\
\hline KOBE & $0.4-0.48$ & $0.7-0.8$ \\
\hline GUJARAT & $0.16-0.24$ & $0.5-0.6$ \\
\hline BOUMERDES & $0.08-0.16$ & $0.3-0.4$ \\
\hline BAM & $0.16-0.24$ & $0.7-0.8$ \\
\hline E-SICHUAN & $0.16-0.24$ & $0.6>0.8$ \\
\hline HAITI & $0.08-0.16$ & $0.3-0.6$ \\
\hline SENDAI & $0.24-0.32$ & $1.1-2.9$ \\
\hline
\end{tabular}




\section{Seismic acceleration recorded during the April 6, 2009 Abruzzo earthquake}

According to the Italian Institute of Geophysics and Volcanology (INGV), the main shock of the L'Aquila earthquake occurred on April 6, 2009, at 3.32 a.m. $\left(M_{\mathrm{L}}=5.8\right.$ and $\left.M_{\mathrm{w}}=6.3\right)$. The epicentre was located at a few kilometres W-SW from the town of L'Aquila. The maximum MCS intensity was: $I=\mathrm{X}$ at Onna $I=$ IX at L'Aquila (73,000 inhabitants). The focal depth was about $8.8 \mathrm{~km} .308$ deaths, 1600 injured, 40,000 homeless, damages of about $€ 30$ billion, plus the incalculable value of monuments. The locations of main shock, foreshocks and aftershocks around the city of L'Aquila are reported in fig. 3.

Most of the deaths took place in vulnerable masonry houses which were subjected to unusually strong motions. Several reports on the main features of the recorded ground motions were compiled by different teams, among which the group of Italian investigators [8,9] under the umbrella of the Italian Geotechnical Association (AGI) and the National Network of Earthquake Engineering Laboratories (ReLUIS) project; detailed reports was also produced by the Geo-Engineering for Extreme Events Reconnaissance (GEER) project [10] on seismological and geotechnical aspects of the earthquake and by Aydan et al. [11] on the damage occurred. The effects on the physical environment are reported, with reference to fractures, large deformations, rock falls, sink holes and liquefaction. The soil liquefaction that occurred at Vittorito is reported in detail by Monaco et al. [12].

Four accelerometric stations (AQG, AQA, AQV, AQM) were located across the Aterno valley (fig. 4) and recorded peak values ranging from about 0.4 to $0.6 \mathrm{~g}$; station $\mathrm{AQK}$ was located in the city and recorded a peak value of about $0.35 \mathrm{~g}$. In table 4 , the recorded ground motion parameters are reported in terms of maximum Peak Ground Acceleration (PGA) and Peak Ground Velocity (PGV) for the three components of each four stations considered. With regard to PGA, the recorded maximum value is $0.65 \mathrm{~g}$ for the $\mathrm{EW}$ component from the AQV recording station, located on alluvial soil, in the middle of the Aterno Valley.

Also, the strong portions of vertical and horizontal motions occurred almost simultaneously due to the short travel paths of $\mathrm{P}$ and $\mathrm{S}$ waves from the fault to the ground surface. This is evident from the severe horizontal motion starting only about $1 \mathrm{~s}$ after the vertical one, with a predominant period of $0.4-0.7 \mathrm{~s}$ for $\mathrm{S}$ waves, while for $\mathrm{P}$ waves, the predominant period is in the range $0.1-0.2 \mathrm{~s}$. These features are consistent with the fundamental frequencies of vibration of one-to-eight-story buildings in L'Aquila and can be particularly dangerous for weak non-ductile systems, such as the many old masonry structures in the area. The predominant frequency is between 1 and $2.5 \mathrm{~Hz}$ for the horizontal components; in particular for the AQV horizontal components, it is $2 \mathrm{~Hz}$. A comparison between the response spectra of AQV and AQG horizontal E-W and N-S components shows that for AQV station resting on soil formation, there are some peaks in the period range $T=0.15-0.5 \mathrm{~s}$ and for AQG station resting on soft rock, the predominant period is $T=0.25 \mathrm{~s}$ for the E-W component and its range is $T=0.2-0.5 \mathrm{~s}$ for the N-S component. 


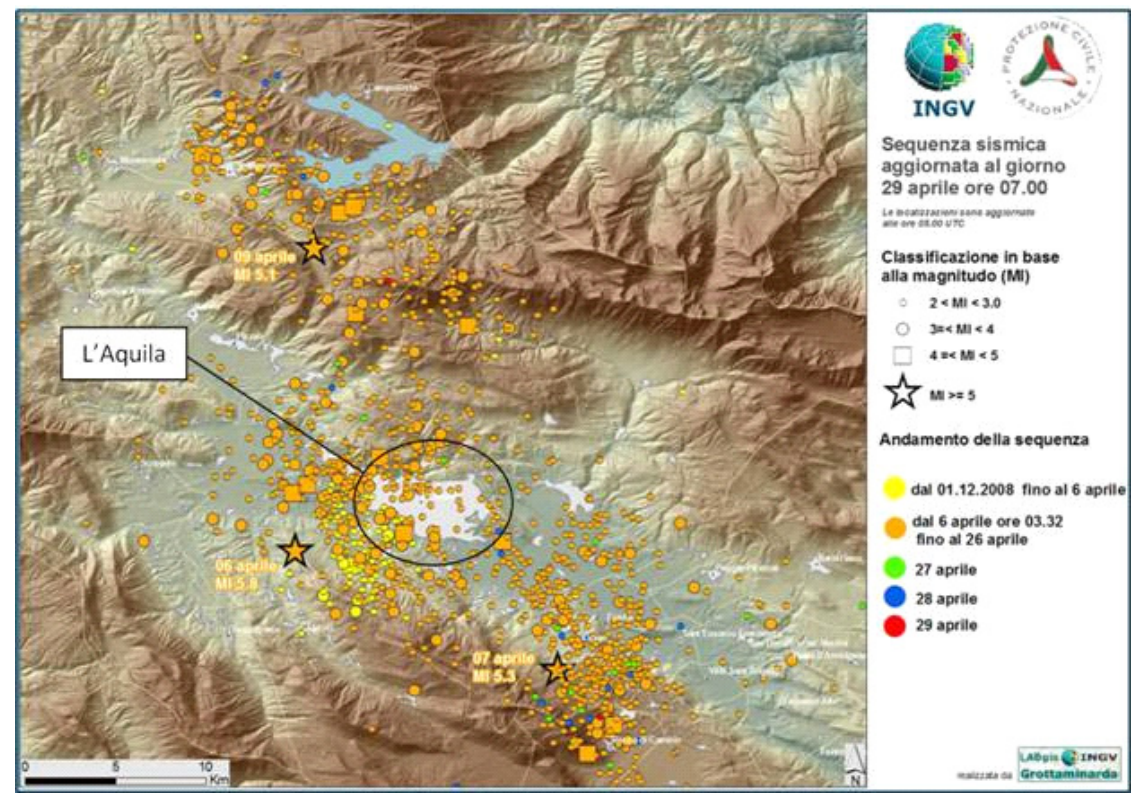

Figure 3: Foreshocks, main shock and aftershocks locations around the city of L'Aquila, after INGV.

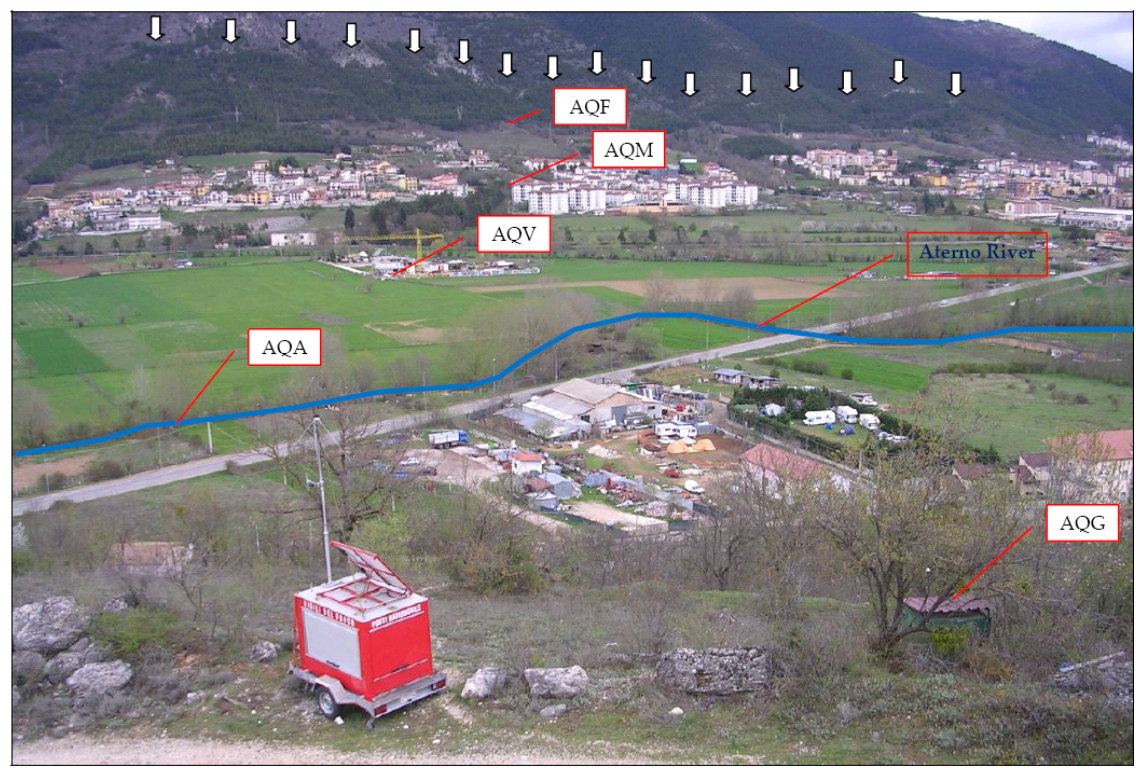

Figure 4: Location of the acceleration stations at the Aterno Valley, recording the Abruzzo April 6, 2009 earthquake [13]. 
Regarding AQK station, located on stiff soil in the city of L'Aquila, the maximum recorded peak NS component of ground acceleration, is $0.35 \mathrm{~g}$; it must be stressed that L'Aquila is located in the vicinity of a normal fault and because of that, the recorded NS component of vertical acceleration (UP) of $0.37 \mathrm{~g}$ is slightly bigger than the horizontal one. It could be interesting to compare the recorded accelerations with those predicted by the new Italian Code [1] for L'Aquila city. According to this Code, the peak ground acceleration is $a_{g}=0.250-0.275 \mathrm{~g}$, as can be read for the specific site from the regulation.

\section{Evaluation of site effects in the middle Aterno Valley}

Seismic response analyses were carried out at the AQV station, located on alluvial soil in the middle of Aterno valley [14]. The subsoil model was built according to the geotechnical data available for AQV station subsoil conditions reported in fig. 5; Fig. 5b shows the $V_{s}$ profile measured by D-H; fig. 5c shows the modified $V_{s}$ profile according to the discontinuity given by the stratigraphy and the general increase of $V_{s}$ with depth. The unit weight increased with depth and soil type from 19 to $22 \mathrm{kN} / \mathrm{m}^{3}$. The bedrock was located at a depth of $46 \mathrm{~m}$, where the shear wave velocity becomes higher than $800 \mathrm{~m} / \mathrm{s}$. The shear modulus decay and damping ratio increase with shear strain, evaluated by Resonant Column Tests, are reported in fig. 6 , referring to different localities. The input accelerograms are reported by Maugeri et al. [14].

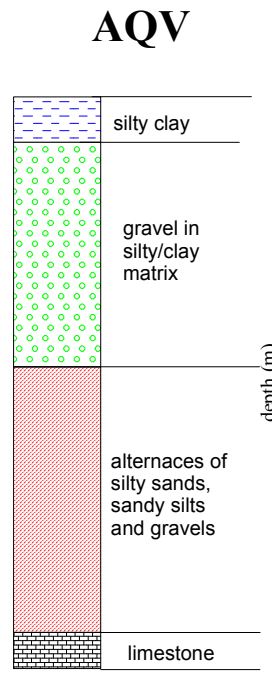

(a)

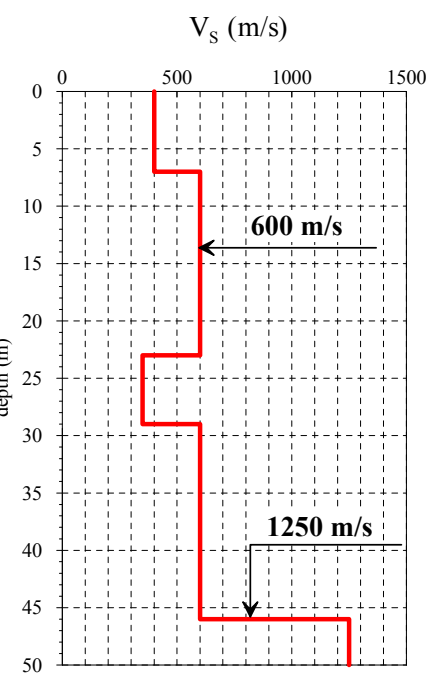

(b)

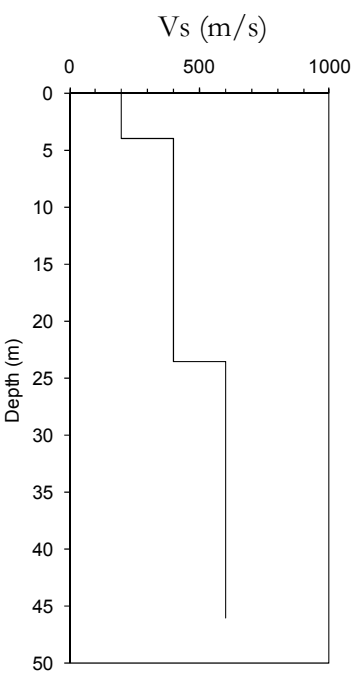

(c)

Figure 5: Shear wave profiles at AQV Recording Station: (a) Soil stratigraphy; (b) shear wave velocity profile obtained by Down Hole (D-H) test;

(c) modified shear wave profile. 


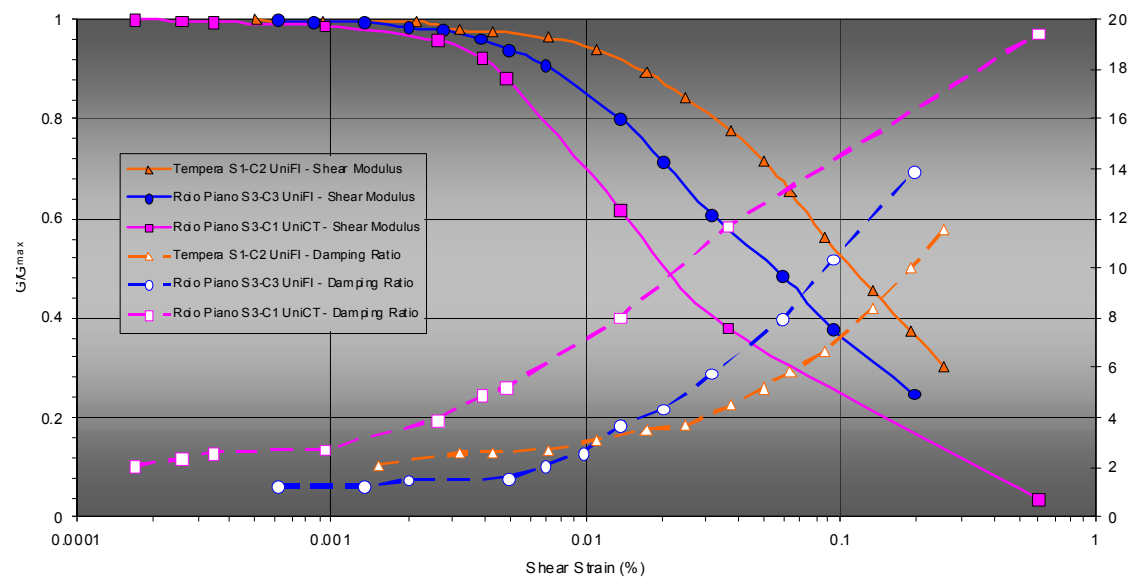

Figure 6: Normalised shear modulus and damping ratio versus shear strain from RC - TS Roio Piano and Tempera tests.

The recorded (table 4) and the computed values of maximum acceleration show an average amplification factor of about $S_{s}=2.5$, which is considerably higher for soil type B than the $S_{s}=1.14$ given by the Italian regulation code and the $S_{s}=1.20$, given by the Eurocode. It must be stressed that, while the horizontal acceleration at the bedrock was in some agreement with the predicted one by the Italian Regulation, the vertical component of acceleration was much higher than that recommended by the Italian Code for the design of geotechnical structures (such as slope, earth retaining wall). In general it is recommended by Italian Code and Eurocode 8 , to consider a vertical acceleration equal to $50 \%$ the horizontal one. Because of the occurrence of a normal fault in the proximity of L'Aquila City, the recorded vertical acceleration was much higher than that recommended by the Regulations and its value was very similar to horizontal acceleration in the AQK station, located in the city of L'Aquila. This last aspect, which is outside the scope of this paper, must be considered by the Code in the future for a better design of geotechnical structures and of buildings resting on the proximity of normal faults.

Site amplification, performed by the EERA code [15], was carried out for all the normalized shear moduli and damping ratios reported in fig. 6 and for different curves given in literature, such as that reported by Kokusho and Esashi [16].

Table 4: Recorded ground motion parameters in terms of maximum Peak Ground Acceleration (PGA) (g) and Peak Ground Velocity (PGV) $(\mathrm{cm} / \mathrm{s})$.

\begin{tabular}{|c|c|c|c|c|c|c|c|c|c|c|c|c|}
\hline & AQG & AQG & AQG & AQA & AQA & AQA & AQV & AQV & AQV & AQK & AQK & AQK \\
& NS & EW & UP & NS & EW & UP & NS & EW & UP & NS & EW & UP \\
\hline PGA & 0.51 & 0.47 & 0.24 & 0.45 & 0.40 & 0.47 & 0.54 & 0.65 & 0.52 & 0.35 & 0.33 & 0.37 \\
\hline PGV & 35.9 & 31.2 & 10.4 & 24.5 & 32.0 & 9.39 & 40.4 & 36.7 & 12.5 & 36.3 & 30.3 & 19.8 \\
\hline
\end{tabular}


The results reported in fig. 7 show that the site responses, evaluated for the normalized shear modulus and damping ratio results obtained at Roio Piano and Tempera localities, are in good agreement with the recorded values of acceleration. Also using the normalized shear modulus and damping ratio given by Kokusho and Esashi [16], the results are slight lower, but sufficiently closed to the recorded one.

Seismic response analyses in the historical centre of L'Aquila have been carried out by Monaco et al. [17]. The site response analysis, performed at the historical building named Palazzo Camponeschi, was carried out for a two-layered soil with an inverse shear wave velocity profile, characterized by $V_{s}=800-1000 \mathrm{~m} / \mathrm{s}$ for the upper layer, with a thickness of about $100 \mathrm{~m}$, and by $V_{s}=600-700 \mathrm{~m} / \mathrm{s}$ for the second layer, resting over the bedrock, placed at a depth of $300 \mathrm{~m}$.

The soil shear wave profile was measured by the Seismic Dilatometer Test (SDMT) in a non-penetrable soil [18]; for the upper layer made by Breccias, the normalized shear modulus and damping ratio were selected from literature results measured in similar soils, for the second layer made by lacustrine silt these values were obtained by Resonant Column Tests performed at Roio Piano [19].

The results, performed according to the EERA code [15] show that the spectral acceleration $S_{a}$ is greater than that given by the Italian regulation NTC [1] particularly for a period ranging between $0.2 \mathrm{~s}$ and $0.4 \mathrm{~s}$, which is the fundamental period more representative for masonry buildings present in the area.

The evidence of low frequency amplification in the city of L'Aquila was underlined by De Luca et al. [20], before the occurrence of the destructive 2009 Abruzzo earthquake.

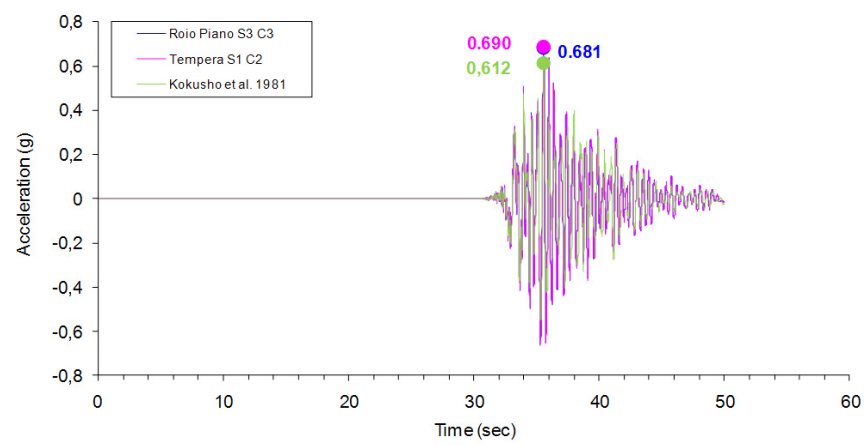

Figure 7: Results of site response analyses evaluated by normalized shear modulus and damping ratio obtained at Roio Piano and Tempera localities.

\section{Evaluation of site effects in the city of L'Aquila}

The paper defines also the ground model on the basis of results obtained by extensive site investigations (boreholes, Down-Hole tests, MASW and SDMT tests) and laboratory tests, carried out in the city of L'Aquila, in the area of Via 
XX Settembre (southern part of the historic centre of the city of L'Aquila) severely damaged by the earthquake, with the aim of performing detailed and accurate site investigation [21-35] for the microzonation of damaged areas including the studied area.

As an example, in fig. 8, the site response analysis at the surface is reported in terms of the acceleration time history for SDMT and MASW profiles, using the deconvoluted time history at the AQG station. The maximum acceleration for the SDMT profile is $a_{g}=0.34 \mathrm{~g}$ while for the MASW M3 is $a_{g}=0.90 \mathrm{~g}$.

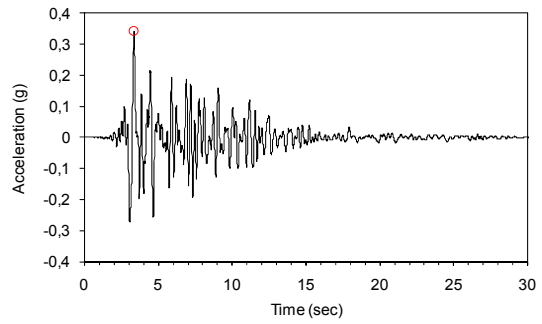

(a)

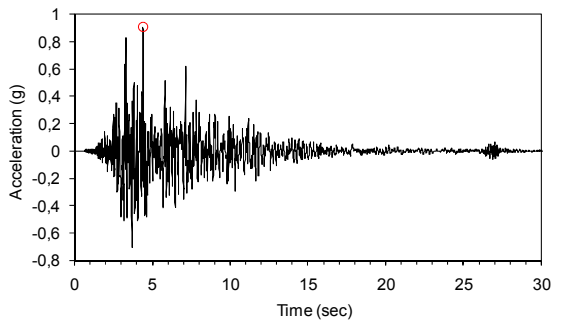

(b)

Figure 8: Time histories of the response at the surface for the geotechnical profiles by SDMT (a) and MASW (b) tests.

In fig. 9a, the profile of maximum acceleration with depth is reported for section S1 and for SDMT and MASW profiles. From fig. 9a it is possible to see that the maximum acceleration at the surface, evaluated for MASW profile, is much higher than that evaluated by SDMT profile, because of the presence of discontinuities in the profile of shear wave velocity at $2 \mathrm{~m}$ and $10 \mathrm{~m}$ depths. In fig. 9b, the pseudo spectral acceleration is reported for SDMT and MASW profiles. Because of the discontinuities in the MASW profile, the soil amplification is higher than that of SDMT profile.

Similar results have been obtained from some other local site response analyses carried out for the same area by the 1-D linear equivalent computer code EERA for the evaluation of the amplification factors of the maximum acceleration $[36,37]$ and also for other areas [38-42].

\section{Conclusions}

The key-point for the evaluation of the seismic risk is the evaluation of the seismic hazard, related to the evaluation of the seismic action by probabilistic or deterministic approaches.

In general, for a low seismicity area, the probabilistic approach is overestimating the seismic action, while for very high seismicity area, it underestimates the seismic action, as in the case of the city of Catania. In the case of the Abruzzo earthquake, accelerations bigger than that given by the Italian Regulation were recorded. This was mainly due to the soil amplification in the soft 


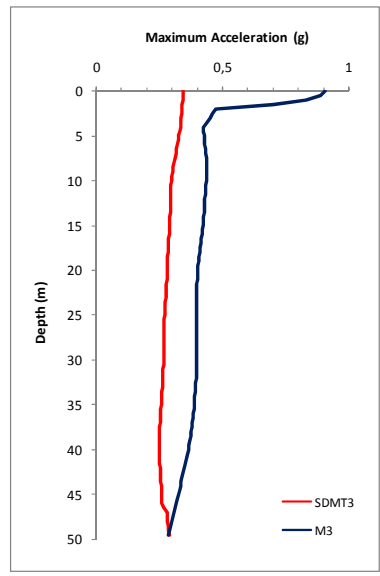

(a)

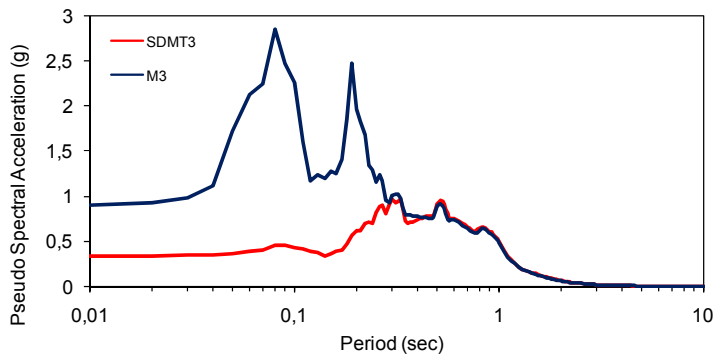

(b)

Figure 9: (a) Profile of maximum acceleration with depth for SDMT and MASW profiles; (b) pseudo spectral acceleration for SDMT and MASW profiles.

soil of Aterno Valley being greater than that given by Italian Regulation. Also in the centre of L'Aquila city, the spectral acceleration given by Italian Regulation is too simple for the evaluation of the soil response in a soil with inverse velocity profile.

\section{References}

[1] NTC, Norme Tecniche per le costruzioni, D. M. 14/01/2008 by the Ministry of Public Works of Italy, G.U. 04/02/2008, 2008.

[2] Maugeri, M., Castelli, F. \& Massimino, M.R., Analysis, modeling and seismic improvement of foundations of existing buildings. Italian Geotechnical Journal, No. 4, pp. 52-122, 2006 (in Italian with extended abstract in English).

[3] Ishihara, K., Perspectives in geotechnics for vastly strong earthquake shaking. Proc. of the $1^{\text {st }}$ Int. Conf. on Performance-Based Design in Earthquake Geotechnical Engineering, IS- Tokyo, 2009.

[4] Ishihara, K., Challenges in perspective in geotechnics for intense earthquake shaking. Proc. of the Seismic Engineering International Conference commemorating the 1908 Messina and Reggio Calabria Earthquake, Reggio Calabria, 2008.

[5] Martelli, A., Forni, M. \& Panza, G., Features, recent application and conditions for the correct use of seismic isolation systems. Earthquake Resistant Engineering Structures VIII, ed. C.A. Brebbia, WIT Press: Southampton, pp. 15-27, 2011.

[6] Faccioli, E., Pessina, V. \& Vecchiotti, M., Risk-UE WP2 meeting, Barcelona, (2002).

[7] Peresan, A. \& Vaccari, F., Integrated seismic hazard assessment: a neo- 
deterministic time-dependent approach. Workshop on Seismic Information Systems for Monitoring and Alert, ASI, Rome, 2011.

[8] Simonelli, A.L., Sica, S., Moccia, F., Penna, A., Lucadamo, C., Mitrione, A., Mosca, P., Moscato, T., Rotella, M., Spatola, M.G. \& Zarra, S., Rapporto preliminare sugli effetti indotti sull'ambiente fisico dalla sequenza sismica dell'aquilano - Ver. 1.5, Working group AGI-ReLUIS, www.reluis.it, 2009.

[9] Monaco, P., Totani, G., Barla, G., Cavallaro, A., Costanzo, A., D’onofrio, A., Evangelista, L., Foti, S., Grasso, S., Lanzo, G., Madiai, C., Maraschini, M., Marchetti, S., Maugeri, M., Pagliaroli, A., Pallara, O., Penna, A., Saccenti, A., Santucci De Magistris, F., Scasserra, G., Silvestri, F., Simonelli, A.L., Simoni, G., Tommasi, P., Vannucchi, G. \& Verrucci, L., Geotechnical aspects of the L'Aquila earthquake. Geotechnical, Geological and Earthquake Engineering, 16, pp. 1-66, 2012.

[10] Stewart, J.P. (ed.), Di Capua, G., Kayen, R.E., Scott Kieffer, D., Button, E., Biscontin, G., Scasserra, G., Lanzo, G., Tommasi, P., Pagliaroli, A., Silvestri, F., d'Onofrio, A., Simonelli, A.L., Puglia, R., Mylonakis, G., Athanasopoulos, G. \& Vlahakis, V., Preliminary Report on the Seismological and Geotechnical Aspects of the April 62009 L'Aquila Earthquake in Central Italy, GEER Association Report No. GEER-016, Version 1, www.geerassociation.org, 2009.

[11] Aydan, O., Kumsar, H., Toprak, S. \& Barla, G., Characteristics of 2009 L'Aquila earthquake with an emphasis on earthquake prediction and geotechnical damage. Journal of the School of Marine Science and Technology, Tokai University, 7(3), pp. 23-51, 2009.

[12] Monaco, P., Santucci De Magistris, F., Grasso, S., Marchetti, S., Maugeri, M. \& Totani, G., Analysis of the liquefaction phenomena in the village of Vittorito (L'Aquila). Bulletin of Earthquake Engineering, 9, pp. 231-261, 2011.

[13] Di Capua, G., Lanzo, G, Luzi, L., Pacor, F., Paolucci, R., Peppoloni, S., Scasserra, G. \& Puglia, R., Caratteristiche geologiche e classificazione di sito delle stazioni accelerometriche della RAN ubicate a L'Aquila. Report S4 Project (http://esse4.mi.ingv.it/), 2009.

[14] Maugeri, M., Simonelli, A.L., Ferraro, A., Grasso, S. \& Penna, A., Recorded ground motion and site effects evaluation for the April 6, 2009 L'Aquila earthquake. Bulletin of Earthquake Engineering, 9, pp. 157-179, 2011.

[15] EERA, http://gees.usc.edu/GEES/Software/EERA2000/Default.htm, 2000.

[16] Kokusho, T. \& Esashi, Y., Cyclic triaxial tests on sands and coarse materials. Proc. of X World Conf. on Soil Mechanics and Foundation Engineering, 1, pp. 673-676, 1981.

[17] Monaco, P., Totani, G., Totani, F., Amoroso, A., Maugeri, M., Grasso, S., Modello di sottosuolo e analisi di risposta sismica locale nel centro storico dell'Aquila. XIV Convegno ANIDIS - L'Ingegneria Sismica in Italia, Bari, 2011.

[18] Totani, G., Monaco, P., Marchetti, S. \& Marchetti, D., VS measurements 
by seismic dilatometer (SDMT) in non-penetrable soils. Proc. of the 17th Int. Conf. on Soil Mechanics and Geotechnical Engineering, eds. M. Hamza, M. Shahien \& Y. El-Mossallamy, 2, pp. 977-980, IOS Press, 2009.

[19] Gruppo di Lavoro, La Microzonazione Sismica dell'area aquilana, Regione Abruzzo, (in press) 2010.

[20] De Luca, G., Marcucci, S., Milana, G. \& Sanò, T., Evidence of lowfrequency amplification in the city of L'Aquila, Central Italy, through a multidisciplinary approach including strong- and weak-motion data, ambient noise, and numerical modeling. Bulletin of the Seismological Society of America, 95(4), pp. 1469-1481, 2005.

[21] Grasso, S. \& Maugeri, M., The road map for seismic risk analysis in a Mediterranean city. Soil Dynamics and Earthquake Engineering, 29(6), pp. 1034-1045, 2009.

[22] Grasso, S. \& Maugeri, M., The seismic microzonation of the City of Catania (Italy) for the maximum expected scenario earthquake of January 11, 1693. Soil Dynamics and Earthquake Engineering, 29(6), pp. 953-962, 2009.

[23] Grasso, S. \& Maugeri, M., The seismic microzonation of the City of Catania (Italy) for the Etna scenario earthquake $(\mathrm{M}=6.2)$ of February 20, 1818. Earthquake Spectra, 28(2), pp. 573-594, 2012.

[24] Grasso, S. \& Maugeri, M., Seismic microzonation studies for the city of Ragusa (Italy). Soil Dynamics and Earthquake Engineering, 56, pp. 86-97, 2014.

[25] Cavallaro, A., Ferraro, A., Grasso, S. \& Maugeri, M., Topographic effects of the Monte Po hill in Catania (Italy). Soil Dynamics and Earthquake Engineering, 43, pp. 97-113, (2012).

[26] Grasso, S. \& Maugeri, M., The seismic dilatometer Marchetti test (SDMT) for evaluating liquefaction potential under cyclic loading. Geotechnical Earthquake Engineering and Soil Dynamics IV, GSP 181, ASCE, Geo Institute, ISBN 978-0-7844-0975-6, p. 15, 2008.

[27] Cavallaro, A., Grasso, S., Maugeri, M. \& Motta, E., An innovative low-cost SDMT marine investigation for the evaluation of the liquefaction potential in the Genova harbour, Italy. Geotechnical and Geophysical Site Characterization 4, eds. R.Q. Coutinho \& P.W. Mayne, Taylor \& Francis Group: London, pp. 637-644, 2012.

[28] Cavallaro, A., Grasso, S., Maugeri, M. \& Motta, E., Site characterisation by in situ and laboratory tests of the sea bed in the Genova Harbour, Italy. Geotechnical and Geophysical Site Characterization 4, eds. R.Q. Coutinho \& P.W. Mayne, Taylor \& Francis Group: London, pp. 415-422, 2012.

[29] Maugeri, M. \& Grasso, S., A road map for seismic prevention of damage. Earthquake Resistant Engineering Structures VI, WIT Transactions on the Built Environment, ed. C.A. Brebbia, WIT Press: Southampton, 93, 2007.

[30] Cavallaro, A., Grasso, S. \& Maugeri, M., Site response analysis for Tito Scalo Area (PZ) in the Basilicata Region. Geotechnical Earthquake Engineering and Soil Dynamics IV, GSP 181, eds. D. Zeng, M.T. Manzari \& D.R. Hiltunen, ASCE, pp. 1-11, 2008.

[31] Grasso, S., Maugeri, M. \& Spina, L., Seismic microzonation of the city of 
Catania for the Etna earthquake ( $\mathrm{M}=6.2)$ of February 20, 1818. Proc. of the 8th US National Conference on Earthquake Engineering, 16, pp. 97039712, 2006.

[32] Cavallaro, A., Grasso, S. \& Maugeri, M., Volcanic soil characterisation and site response analysis in the city of Catania. Proc. of the 8th US National Conference on Earthquake Engineering, 2, pp. 835-844, 2006.

[33] Grasso, S. \& Maugeri, M., Vulnerability of physical environment of the City of Catania using GIS technique. Advances in Earthquake Engineering, 14, pp. 155-175, 2005.

[34] Bonaccorso, R., Grasso, S., Lo Giudice, E. \& Maugeri, M., Cavities and hypogeal structures of the historical part of the City of Catania. Advances in Earthquake Engineering, 14, pp. 197-223, 2005.

[35] Ligresti, D. \& Grasso S., Historical view of the damage caused by the 1693 Catania earthquake and the reconstruction activities. Disaster Management and Human Health Risk: Reducing Risk, Improving Outcomes, eds. K. Duncan \& C.A. Brebbia, WIT Press: Southampton, pp. 323-331, 2009.

[36] Maugeri, M., Totani, G., Monaco, P. \& Grasso, S., Seismic action to withstand the structures: the case history of 2009 Abruzzo earthquake. Earthquake Resistant Engineering Structures VIII, ed. C.A. Brebbia, WIT Press: Southampton, pp. 3-14, 2011.

[37] Monaco, P., Totani, G., Totani, F., Grasso, S. \& Maugeri, M., Site effects and site amplification due to the 2009 Abruzzo earthquake. Earthquake Resistant Engineering Structures VIII, ed. C.A. Brebbia, WIT Press: Southampton, pp. 29-40, 2011.

[38] Grasso, S., Laurenzano, G., Maugeri, M. \& Priolo, E., Seismic response in Catania by different methodologies. Advances in Earthquake Engineering, 14, pp. 63-79, 2005.

[39] Grasso, S. \& Maugeri, M., Site effects in the cultural heritage areas of the City of Catania. Advances in Earthquake Engineering, 14, pp. 133-152, 2005.

[40] Condarelli, D., Grasso, S., Maugeri, M., Langer, H., Pitilakis, K. \& Manakou, M., A methodology to design bedrock input motion using noise measurements. Proc. of the $17^{\text {th }}$ Int. Conf. on Soil Mechanics and Geotechnical Engineering, Alexandria, Egypt, pp. 945-948, doi: 10.3233/978-1-60750-031-5-945, 2009.

[41] Grasso, S. \& Maugeri, M., The interdisciplinary activity for seismic risk analysis in a Mediterranean city. Management Information Systems, 9, pp. 63-80, 2004.

[42] Maugeri, M. \& Grasso, S., Liquefaction potential evaluation at Catania Harbour (Italy). WIT Transactions on the Built Environment, 132, pp. 69$81,2013$. 